J. Lake Sci. (湖泊科学), 2020, 32(5): 1508-1518

DOI 10. 18307/2020. 0522

(c) 2020 by Journal of Lake Sciences

\title{
东洞庭湖浮游藻类粒级结构组成及其关键影响因子
}

\author{
李胜男 ${ }^{1,2}$, 熊丽萍 ${ }^{1,3}$, 彭 华 ${ }^{1}$, 余 丽 $^{4}$, 纪雄辉 ${ }^{1,3 * *}$ \\ ( 1 : 湖南省农业科学院湖南省农业环境生态研究所,农业部长江中游平原农业环境重点实验室,长沙 410125) \\ ( 2 : 湖泊与环境国家重点实验室,南京 210008) \\ (3: 湖南大学研究生院隆平分院, 长沙 410125) \\ ( 4 : 安徽建筑大学环境与能源工程学院,合肥 230601)
}

摘 要: 不同粒径大小浮游澡类的养分吸收速率、沉降特性和能流方向等都不相同, 浮游藻类生物量的粒级组成变化对 湖泊生态系统的结构与功能具有重要影响. 为了解通江湖泊浮游藻类粒级组成演替规律及其驱动机制, 于 2018 年 9 月一 2019 年 9 月对东洞庭湖进行了年度采样调查, 研究了不同粒级浮游藻类的时空分布特征及其与环境因子的关系. 结果表 明: 东洞庭湖浮游藻类叶绿素 $a$ 总浓度呈现显著的时空分布差异; 季节上表现为夏季 $(22.43 \mu \mathrm{g} / \mathrm{L})>$ 秋季 $(16.95 \mu \mathrm{g} / \mathrm{L})>$ 春季 $(11.69 \mu \mathrm{g} / \mathrm{L})>$ 冬季 $(3.28 \mu \mathrm{g} / \mathrm{L})$, 空间上表现为北部湖区 $(26.12 \mu \mathrm{g} / \mathrm{L})>$ 南部湖区 $(15.81 \mu \mathrm{g} / \mathrm{L})>$ 东部行洪道 $(5.88$ $\mu \mathrm{g} / \mathrm{L})$. 纳微型藻 $(3 \sim 20 \mu \mathrm{m})$ 是东洞庭湖浮游藻类生物量的主要贡献者, 其在冬季优势度最高, 为 $68.0 \%$; 春季开始, 超微 型藻 $(0 \sim 3 \mu \mathrm{m})$ 的贡献量逐渐增加, 到夏季达到最高值, 为 $42.1 \%$; 粒径最大的微型藻 ( $>20 \mu \mathrm{m})$ 占比最低, 全年平均占比 $16.2 \%$. RDA 限制性排序结果表明, 不同粒级浮游藻类对环境因子的响应趋势相同, 但适应能力不同; 温度、水位、营养盐 和 $\mathrm{pH}$ 等是影响东洞庭湖浮游藻类粒级结构的重要因素.

关键词: 东洞庭湖; 叶绿素 $a$; 粒级结构;浮游藻类;通江湖泊

\section{Size-structure of phytoplankton biomass and driving factors in east Lake Dongting*}

\author{
LI Shengnan ${ }^{1,2}$, XIONG Liping ${ }^{1,3}$, PENG Hua ${ }^{1}, \mathrm{YU} \mathrm{Li}^{4} \& \mathrm{JI}$ Xionghui ${ }^{1,3 * *}$ \\ (1: Key Laboratory of Agro-Environment in Midstream of Yangtze Plain, Ministry of Agriculture, Hunan Institute of Agro-En- \\ vironment and Ecology, Hunan Academy of Agricultural Sciences, Changsha 410125, P.R. China) \\ (2: State Key Laboratory of Lake Science and Environment, Nanjing 210008, P.R.China) \\ (3: Longping Branch of Graduate School of Hunan University, Changsha 410125, P.R. China) \\ (4: School of Environment and Energy Engineering, Anhui Jianzhu University, Hefei 230601, P.R.China)
}

Abstract: Cell size is an important element determining phytoplankton physiological and ecological processes, including nutrient uptake, sinking and grazing; thus, phytoplankton size-structure plays an important role in the structure and function of lake ecosystem. To understand the succession patterns and driving factors of total chlorophyll- $a$ and size structure of phytoplankton, field in-situ investigation was conducted from September 2018 to September 2019 in the east Lake Dongting, a Yangtze River- connected lake. The total phytoplankton chlorophyll- $a$ biomass showed significant seasonality and spatiality. The highest concentration of total chlorophyll- $a$ was observed in summer $(22.43 \mu \mathrm{g} / \mathrm{L})$, followed by autumn $(16.95 \mu \mathrm{g} / \mathrm{L})$, spring $(11.69 \mu \mathrm{g} / \mathrm{L})$ and winter ( $3.28 \mu \mathrm{g} / \mathrm{L})$. Spatially, the total phytoplankton chlorophyll- $a$ was highest in the north $(26.12 \mu \mathrm{g} / \mathrm{L})$ and lowest in the east ( 5.88 $\mu \mathrm{g} / \mathrm{L})$ of the lake. Phytoplankton was overwhelmingly dominated by nanophytoplankton (3-20 $\mu \mathrm{m})$. The proportion of nanophytoplankton to total phytoplankton chlorophyll-a biomass was highest in winter $(68.0 \%)$, whereas the proportion of picophytoplankton $(0-3 \mu \mathrm{m})$ increased gradually in spring and peaked in summer $(42.1 \%)$. The contribution of microplankton $(>20 \mu \mathrm{m})$ to total phytoplankton chlorophyll-a biomass was lowest with a mean of $16.2 \%$ all year round. The results of redundancy analysis indicated

* 2019-11-08 收稿; 2020-01-19 收修改稿.

国家自然科学基金项目 (31800388,41601203)、湖南省自然科学基金项目 (2019JJ50314)、湖泊与环境国家重点实 验室开放基金项目 (2018SKL008) 和湖南省农业科技创新资金项目 (2018QN34)联合资助.

** 通信作者;E-mail: jixionghui@ hunaas.cn. 
that phytoplankton with different cell sizes showed similar responsive trends to environmental changes, while their adaptabilities were different. Temperature, water levels, nutrients and $\mathrm{pH}$ were the key factors explaining size-structure of phytoplankton in east Lake Dongting.

Keywords: East Lake Dongting; chlorophyll- $a$; size structure; phytoplankton ; river-connected lake

浮游藻类是水生态系统中最重要的初级生产者. 根据粒径大小可将浮游藻类分为超微型藻 $(<3 \mu \mathrm{m})$ 、 纳微型藻 (3 20 $\mu \mathrm{m})$ 和微型藻 $(>20 \mu \mathrm{m})$. 不同粒径大小浮游藻类的生长速率、对营养要素的摄人速率、在 食物网中的能流去向和沉降特性等均不同 ${ }^{[1-3]}$, 因而了解浮游藻类的粒级结构特征对于研究水体生态系统 的物质流动、能流结构和湖泊碳通量等都具有重要意义.

藻细胞对营养盐的吸收速率与其半径的平方呈反比 ${ }^{[4-5]}$, 因此, 大粒径的藻类比小粒径的藻类更容易受 到营养盐限制 ${ }^{[5]}$. 一般, 在贫营养水体中主要为超微型藻类占优势, 而随着营养水平的升高, 微型和小型藻 类的贡献率逐渐增加 ${ }^{[6-8]}$. 王军静在白洋淀的调查发现,小型和微型浮游藻类是富营养化水体白洋淀叶绿素 的主要贡献者 ${ }^{[9]}$. 在黄海冷水团水域, 与温度相比, 营养盐水平对不同粒级浮游藻类生物量变化的影响更为 重要 ${ }^{[10]}$. 除此之外, 由于小粒径浮游藻类色素受到的包裹效应 (package effect) 较小, 对光量子的利用效率更 高 ${ }^{[1-12]}$, 在弱光条件下更具竞争优势; 因此, 即使是在富营养水体中, 超微型藻类仍可能具有较强的竞争优 势. 更为重要的是, 细胞粒径也是影响浮游藻类新陈代谢速率的关键: 极小和极大的细胞具有相似的新陈代 谢率, 而中等大小的细胞新陈代谢率最快, 这也是大部分的藻类水华都主要由中等粒径藻类组成的重要原 因 ${ }^{[13-14]}$. 因此, 浮游藻类的粒级结构变化很大程度地反应了水环境条件 (尤其是营养水平) 的变化, 是评价水 环境质量发展趋势的重要依据.

目前, 国内对于浮游藻类粒级结构的报道主要集中在海洋生态系统中, 研究区域已基本覆盖我国主要 海域,包括渤海、黄海、东海、台湾海峡及南大洋等 ${ }^{[15-18]}$, 而淡水环境中的同类研究报道相对较少. 长江中下 游地区分布着大量的浅水湖泊,这些湖泊的特征各异, 在人类生产和生活中都发挥着极其重要的经济和生 态作用, 同时湖泊功能也都受到了不同程度的损害, 甚至出现富营养化问题. 然而, 该区域研究主要集中在 浮游藻类种群结构的变化, 而忽略了粒级结构变化. 本研究以洞庭湖泊群中最大、保存最完好的主体湖盆东 洞庭湖为研究对象, 通过为期 1 年的野外监测和调查, 结合多元统计分析, 揭示东洞庭湖浮游藻类群落的粒 级结构组成情况及其演替规律, 探讨影响不同粒级浮游藻类生长的关键环境因子, 为洞庭湖水环境健康评 价及湖泊生态功能研究提供基础数据和科学依据.

\section{1 材料与方法}

\section{1 研究区域概况}

洞庭湖是我国第二大淡水湖, 总面积约 $2691 \mathrm{~km}^{2}$, 洪道面积 $1307 \mathrm{~km}^{2}$, 是承纳湘、资、沅、澧 “四水” 和吞 吐长江的过水性洪道型湖泊, 同时也是国际重要湿地. 由于资源丰富, 其在洞庭湖生态经济区的发展中起着 至关重要的作用. 随着经济的发展, 洞庭湖水质呈恶化趋势, 尤其是东洞庭湖区, 富营养化严重 ${ }^{[19]}$. 东洞庭 湖, 位于洞庭湖东北隅, 作为洞庭湖湖泊群中最大、保存最完好的主体湖盆, 其水域面积占洞庭湖湖区总面 积的 $55 \%$, 是整个洞庭湖湖水最终汇人长江的聚集水域, 其健康程度不仅能直接反映洞庭湖区的生态环境 质量, 并可能直接影响长江中游荆江段水质.

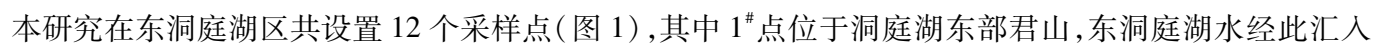
湘江行洪道流人长江; $2^{\#} \sim 5^{\#}$ 点位于东洞庭湖北部湖区; $6^{\#} \sim 9^{\#}$ 点位于东洞庭湖南部湖区; $10^{\#} \sim 12^{\#}$ 点位于东 洞庭湖东部湘江行洪道上. 由于受洞庭湖水位影响, 北部和南部湖区部分或全部点位在冬季枯水期 (图 1 灰 蓝色区域, 2018 年 12 月- 2019 年 3 月)未能采集.

\section{2 样品采集及水质分析}

于 2018 年 9 月 -2019 年 9 月,每月对东洞庭湖进行一次采样调查, 其中 9-11 月为秋季、 12 月一次年 2 月为冬季、3-5 月为春季、6-8 月为夏季. 通过 GPS 系统定位, 利用采水器采集 $0 \sim 1.2 \mathrm{~m}$ 范围内的表层水 样, 混合均匀后, 装人无菌塑料瓶, 冷藏运回实验室进行分析. 现场采用多参数水质分析仪 (Aquaread AP- 


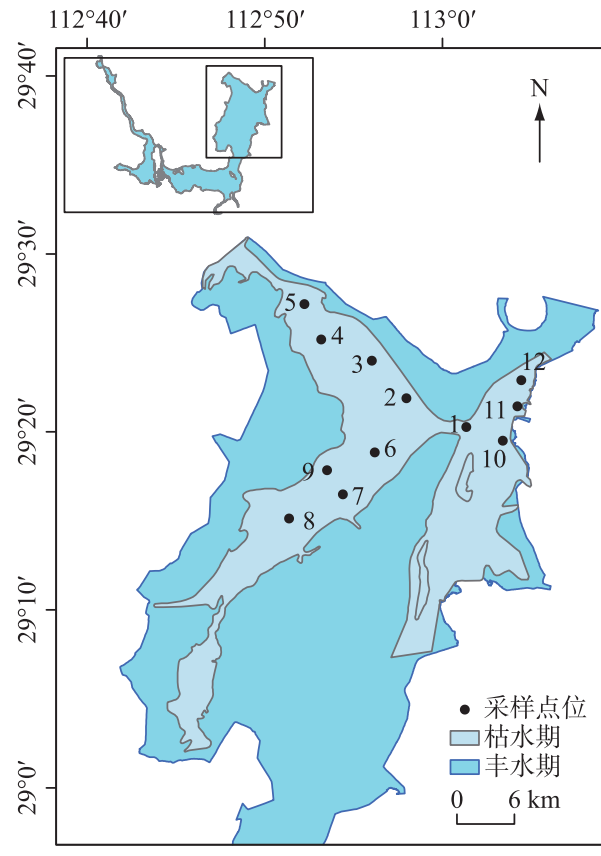

图 1 东洞庭湖位置及采样点位

Fig.1 Location of east Lake Dongting and distribution of the sampling sites
$2000, \mathrm{UK})$ 原位测定水温 ( $\mathrm{T}) 、 \mathrm{pH}$ 、溶解氧 ( DO )、浊度 (Turb)、氧化还原电位 $(\mathrm{ORP})$ 和电导率 $(\mathrm{EC})$ ) 等指标; 利用 塞氏黑白盘法测定水体透明度 (SD); 利用便携式水深探测 仪 (Speedtech SM-5A，Unionville，VA，USA) 测定水深 (Depth). 用采样当日洞庭湖城陵矶站水位表示水位 (WL) 变化.

利用硫酸盐氧化法测定总氮 $(T N)$ 、总磷 $(T P)$ 及高锰 酸盐指数 $\left(\mathrm{COD}_{\mathrm{Mn}}\right)^{[20]}$. 取 $\mathrm{GF} / \mathrm{C}$ 玻璃纤维滤膜 $(0.8 \mu \mathrm{m}$ 孔 径, Whatman) 过滤后的水样, 测定硝态氮 $\left(\mathrm{NO}_{3}^{-}-\mathrm{N}\right)$ 、氨氮 $\left(\mathrm{NH}_{3}-\mathrm{N}\right)$ 、磷酸盐 $\left(\mathrm{PO}_{4}^{3-}-\mathrm{P}\right)$ 和溶解性有机碳 ( DOC). 其中 $\mathrm{NO}_{3}^{-}-\mathrm{N} 、 \mathrm{NH}_{3}-\mathrm{N}$ 和 $\mathrm{PO}_{4}^{3-}-\mathrm{P}$ 浓度用 Skalar 自动分析系统测 定, DOC 浓度通过高温氧化法利用 Shimadzu TOC 分析仪 (Model 5000, Tokyo, Japan) 测定. 过滤的 GF/C 滤膜采用 Tris-HCl 提取法, 利用苂光分光光度计测定藻蓝素 $(P C$, 表 征蓝藻浓度 ${ }^{[21]}$.

\section{3 不同粒级浮游藻类生物量测定}

本研究利用叶绿素 $a($ Chl. $a)$ 浓度表征浮游藻类生物 量. 采用分级过滤法,取部分水样依次通过 $20 、 3$ 和 $0.2 \mu \mathrm{m}$ 孔径的滤膜 (Merck Millipore Ltd., Tullagreen, Carrigtwohill Co. Cork, IRL) 分别收集微型藻、纳微型藻和超微型藻类. 过滤过程中根据过滤速度及时更换滤膜, 以尽可能降低因 孔径堵塞,截留小粒径藻类而引起的误差. 滤膜采用 $90 \%$

丙酮提取法, 于暗处 $-4^{\circ} \mathrm{C}$ 静置提取至少 $12 \mathrm{~h}$, 离心取上清液, 再用 $90 \%$ 丙酮定容, 使用苂光分光光度计 ( RF5301 ) 测定 Chl. $a$ 浓度 ${ }^{[21]} .0 .2 、 3$ 和 $20 \mu \mathrm{m}$ 滤膜收集的藻细胞 Chl. $a$ 分别代表超微型藻 (Chl_pico)、纳微型藻 (Chl_nano) 和微型藻 (Chl_micro) 的 Chl. $a$ 浓度, 三者之和即为总浮游藻类 Chl. $a$ 浓度; 并利用 pChl_pico、 pChl_nano 和 pChl_micro 分别代表超微型藻、纳微型藻和微型藻类 Chl. $a$ 所占的比例.

\section{4 数据分析与统计}

通过双因素方差分析 Two-way ANOVAs 对洞庭湖环境因子的时空分布进行差异显著性分析. 利用 Spearman 相关系数检测浮游藻类生物量及不同粒级浮游藻类相对比例与主要水环境因子的相关性. 利用多 元逐步回归分析进一步探究影响浮游藻类 Chl. $a$ 和 PC 浓度的关键影响因子, 利用矫正 $R^{2}$ 判定系数表征回 归模型中环境因子变异对浮游藻类 Chl. $a$ 和 PC 浓度变异的解释率; 通过相对权重法分析各因子的对解释变 量预测的相对重要性. 利用冗余分析 (RDA) 分析浮游藻类粒级组成与环境因子的相关性,并且通过环境因子 预选篮选出对浮游藻类粒级组成变化解释率最高的环境因子. 所有统计分析和作图均在 R (version 3.5.3, http://cran.r-project.org) 环境下完成.

\section{2 结果与分析}

\section{1 湖泊理化特性分析}

2018 年 9 月- 2019 年 9 月全年检测期间, 东洞庭湖水环境因子均值及其变化范围如表 1 所示. 双因素 方差分析结果表明, 东洞庭湖大部分水环境因子时空变化差异显著. 在时间上, 洞庭湖为典型的过水性洪道 型湖泊,受水位影响, 不同季节水深变化明显, 夏季为丰水期, 春季为水位上升期, 秋季为水位下降期, 冬季 水位最低 (图 2); 其次, 东部行洪道水深显著高于北部和南部湖区, 而水体透明度显著低于北部和南部湖区 (图 3). 受亚热带季风气候影响, 东洞庭湖水温表现出明显的季节性差异, 全年平均水温 $22.01^{\circ} \mathrm{C}$, 冬季最低 温为 $5.1^{\circ} \mathrm{C}$, 夏季最高温达到 $32.8^{\circ} \mathrm{C}$. 水体 $\mathrm{pH}$ 和 $\mathrm{DO}$ 浓度分别与水温呈现相似和相反的时间变化规律. 水体 $\mathrm{TN}$ 浓度在平均浓度 $1.49 \mathrm{mg} / \mathrm{L}$ 左右波动, 南部和北部湖区均在夏季达到最低值. TP 浓度在春季水位上升期 
表 1 东洞庭湖全年环境因子和浮游藻类粒级组成均值及其时空变化的差异显著性分析结果 “

Tab.1 Means ( minimum-maximum) of environmental parameters and size fractioned chlorophyll- $a$ of phytoplankton in east Lake Dongting

\begin{tabular}{|c|c|c|c|}
\hline \multirow{2}{*}{ 指标 } & \multirow{2}{*}{ 平均值 (范围) } & \multicolumn{2}{|c|}{ Two-way ANOVA } \\
\hline & & 季节 & 区域 \\
\hline $\mathrm{TN} /(\mathrm{mg} / \mathrm{L})$ & $1.49(0.44 \sim 2.72)$ & 0.024 & $<0.001$ \\
\hline $\mathrm{NO}_{3}^{-}-\mathrm{N} /(\mathrm{mg} / \mathrm{L})$ & $1.07(0 \sim 2.12)$ & 0.079 & $<0.001$ \\
\hline $\mathrm{NH}_{3}-\mathrm{N} /(\mathrm{mg} / \mathrm{L})$ & $0.21(0 \sim 0.6)$ & $<0.001$ & 0.366 \\
\hline $\mathrm{TP} /(\mathrm{mg} / \mathrm{L})$ & $0.10(0.01 \sim 0.71)$ & 0.072 & 0.634 \\
\hline $\mathrm{PO}_{4}^{3-}-\mathrm{P} /(\mathrm{mg} / \mathrm{L})$ & $0.03(0 \sim 0.15)$ & $<0.001$ & 0.067 \\
\hline $\mathrm{N}: \mathrm{P}$ & $24.57(1.16 \sim 86)$ & 0.003 & 0.628 \\
\hline $\mathrm{COD}_{\mathrm{Mn}} /(\mathrm{mg} / \mathrm{L})$ & $35.25(0 \sim 215.2)$ & $<0.001$ & 0.006 \\
\hline $\mathrm{DOC} /(\mathrm{mg} / \mathrm{L})$ & $6.40(0.01 \sim 37.39)$ & $<0.001$ & 0.034 \\
\hline $\mathrm{SD} / \mathrm{m}$ & $0.41(0.1 \sim 1.2)$ & $<0.001$ & 0.001 \\
\hline Depth/m & $4.49(0.5 \sim 16)$ & $<0.001$ & $<0.001$ \\
\hline $\mathrm{T} /{ }^{\circ} \mathrm{C}$ & $22.01(5.1 \sim 32.8)$ & $<0.001$ & 0.508 \\
\hline $\mathrm{pH}$ & $8.01(6.76 \sim 8.98)$ & $<0.001$ & $<0.001$ \\
\hline $\mathrm{ORP} / \mathrm{mV}$ & $179.71(129.3 \sim 320.4)$ & 0.067 & 0.089 \\
\hline $\mathrm{DO} /(\mathrm{mg} / \mathrm{L})$ & $8.69(5.2 \sim 12.96)$ & $<0.001$ & $<0.001$ \\
\hline $\mathrm{EC} /(\mu \mathrm{S} / \mathrm{cm})$ & $318.34(192 \sim 544)$ & $<0.001$ & $<0.001$ \\
\hline Turb/NTU & $26.63(0 \sim 232)$ & $<0.001$ & 0.009 \\
\hline $\mathrm{PC} /(\mu \mathrm{g} / \mathrm{L})$ & $7.31(0.3 \sim 103.11)$ & $<0.001$ & $<0.001$ \\
\hline Chl. $a /(\mu \mathrm{g} / \mathrm{L})$ & $15.95(1.13 \sim 68.51)$ & $<0.001$ & $<0.001$ \\
\hline pChl_pico /\% & $31.1(4.1 \sim 67.9)$ & $<0.001$ & 0.814 \\
\hline pChl_nano/\% & $52.8(19.0 \sim 87.6)$ & $<0.001$ & 0.022 \\
\hline pChl_micro/\% & $16.2(1.3 \sim 56.6)$ & $<0.001$ & 0.001 \\
\hline
\end{tabular}

*加粗字体表示差异显著 $(P<0.05)$.
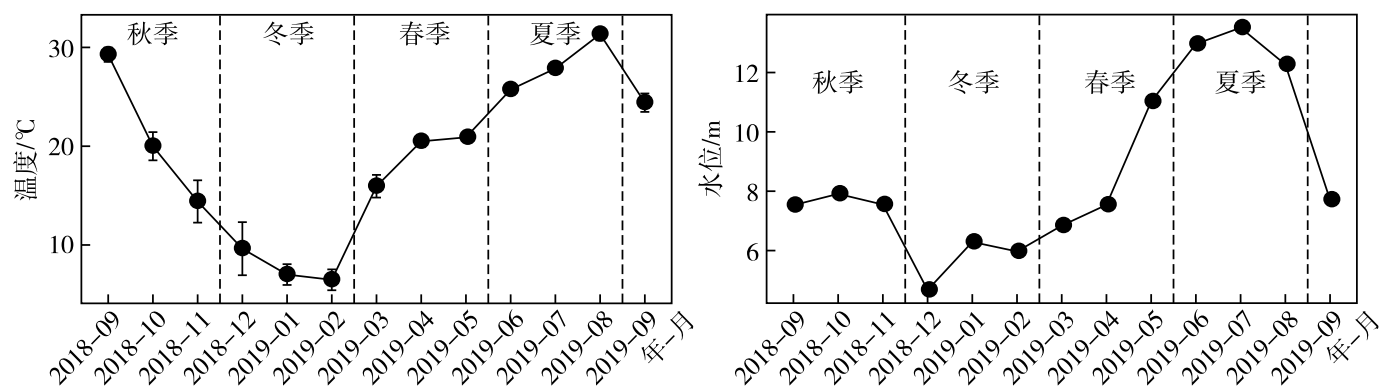

图 2 东洞庭湖水温和水位周年变化

Fig.2 The temporal changes of temperature and water levels in east Lake Dongting

达到峰值, 其他时间均保持相对稳定, 波动不明显. 水体 $\mathrm{COD}_{\mathrm{Mn}}$ 和 $\mathrm{DOC}$ 浓度均在冬季最低(图 3 ). 在空间上, 东部行洪道水体理化因子显著区别于南部和北部湖区 (图 3). 其中东部行洪道 $\mathrm{pH}$ 、 EC 和 DO 浓度 (尤其是 夏季) 均显著低于北部和南部湖区, 而 Turb、ORP 和 TN 浓度均显著高于北部和南部湖区.

\section{2 东洞庭湖浮游藻类浓度变化及其影响因子}

东洞庭湖浮游藻类 Chl. $a$ 全年的平均浓度为 $15.95 \mu \mathrm{g} / \mathrm{L}$, 变化范围为 $1.13 \sim 68.51 \mu \mathrm{g} / \mathrm{L}$, 时空分布差异 明显 (表 1 , 图 4). 空间上, 北部湖区浮游藻类 Chl. $a$ 浓度最高, 平均值为 $26.12 \mu \mathrm{g} / \mathrm{L}$; 其次为南部湖区, 平均 


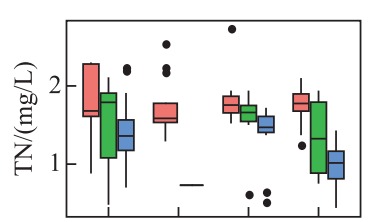

白东部湖区白南部湖区白北部湖区
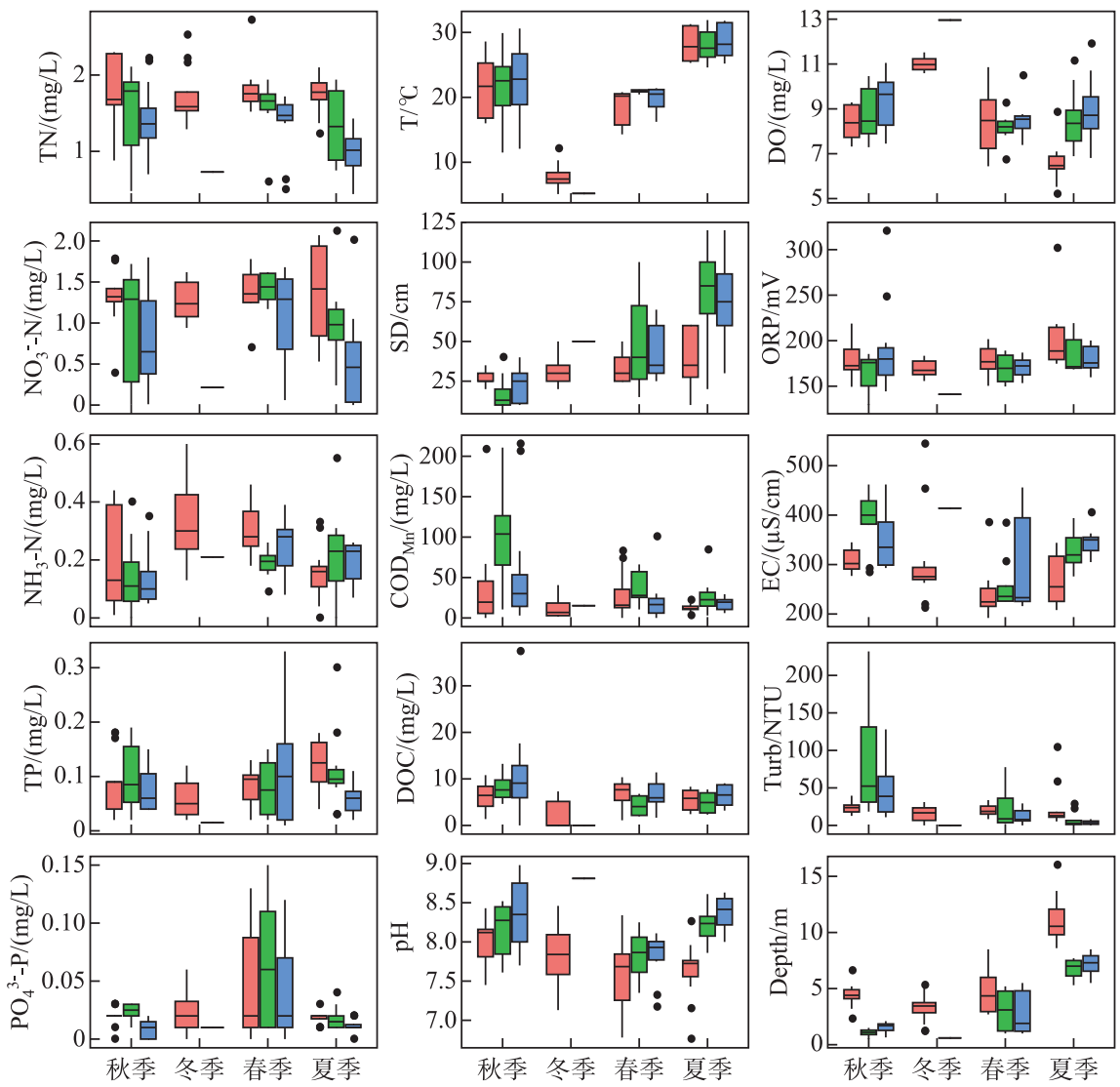

图 3 东洞庭湖主要水环境因子的时空差异

Fig.3 Temporal and spatial variations of the main physiochemical parameters in east Lake Dongting

Chl. $a$ 浓度为 $15.81 \mu \mathrm{g} / \mathrm{L}$; , 东部行洪道上浮游藻类 Chl. $a$ 浓度最低, 平均为 $5.88 \mu \mathrm{g} / \mathrm{L}$. 同时, 浮游藻类 Chl. $a$ 浓度还表现出明显的季节波动, 冬季最低, 平均为 $3.28 \mu \mathrm{g} / \mathrm{L}$; 从春季开始逐渐升高, 到夏季达到最高值, 平 均浓度达到 $22.43 \mu \mathrm{g} / \mathrm{L}$; 到秋季开始逐渐降低. PC 浓度可用于表征水体蓝藻生物量. 总体上, 东洞庭湖 PC

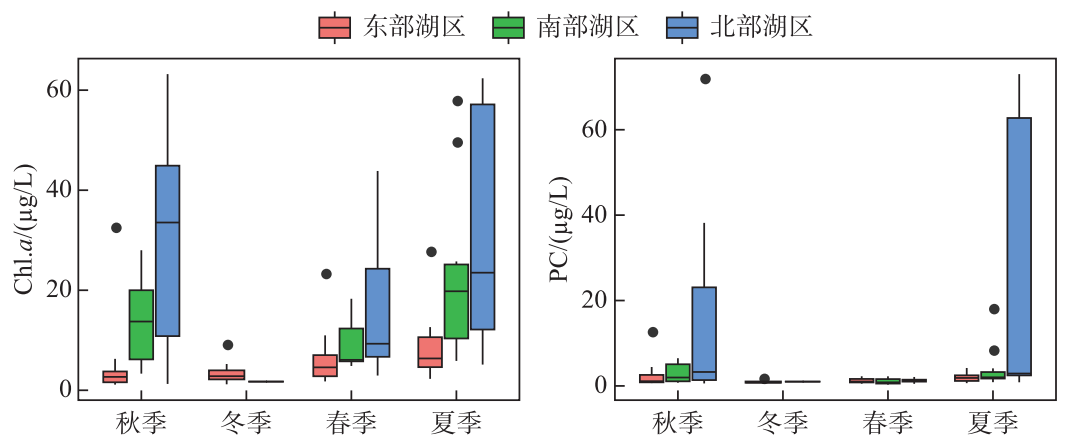

图 4 东洞庭湖浮游藻类叶绿素 $a$ 和 PC 浓度的时空变化

Fig.4 Temporal and spatial variations of phytoplanklon chlorophyll- $a$ and phycocyanobilin concentrations in east Lake Dongting 
浓度与浮游藻类 Chl. $a$ 浓度呈现相似的时空分布规律 (图 4). 北部湖区 PC 浓度最高, 尤其是在夏季,最高浓 度可达到 $103.11 \mu \mathrm{g} / \mathrm{L}$, 部分区域出现水华; 秋季开始逐渐降低, 冬季达到最低值. 而东部和南部湖区全年 PC 浓度均保持在较低水平, 平均浓度分别为 1.64 和 $2.80 \mu \mathrm{g} / \mathrm{L}$.

相关分析结果表明,东洞庭湖浮游藻类总 Chl. $a$ 浓度与水体氮、磷营养盐浓度和 N : P 比值均呈显著负相 关 (表 $2, P<0.05)$, 而与水温、电导率、 $\mathrm{pH} 、 \mathrm{DOC} 、 \mathrm{COD}_{\mathrm{Mn}}$ 和水位等呈显著正相关 $(P<0.01) ; \mathrm{PC}$ 浓度与环境因 子的相关性与 Chl. $a$ 浓度相似. 为进一步探寻对浮游藻类 Chl. $a$ 和 PC 浓度变化解释率最高的关键环境因 子, 进行了逐步回归分析及因子相对重要性分析, 结果表明进人最终模型的环境因子中, $\mathrm{NO}_{3}^{-}-\mathrm{N} 、 \mathrm{~T}$ 和 $\mathrm{DO}$ 均 是解释东洞庭湖浮游藻类总 Chl. $a$ 和 PC 浓度变化相对权重最高的因子(图 5 ).

表 2 浮游藻类叶绿素 $a$ 及其粒级组成与环境因子的 Spearman 相关系数

Tab.2 Spearman correlations among size fractionated cholorophyll- $a$ and environmental parameters

\begin{tabular}{|c|c|c|c|c|c|}
\hline 环境因子 & $\mathrm{PC}$ & Chl. $a$ & 超微型藻比例 & 纳微型藻比例 & 微型藻比例 \\
\hline $\mathrm{NO}_{3}^{-}-\mathrm{N}$ & $-0.642^{* * * *}$ & $-0.659^{* * *}$ & -0.078 & $0.311^{* * * *}$ & $-0.286^{* * *}$ \\
\hline $\mathrm{NH}_{3}-\mathrm{N}$ & $-0.227^{* * *}$ & $-0.257^{* *}$ & $-0.229^{* *}$ & $0.359^{* * *}$ & -0.063 \\
\hline $\mathrm{PO}_{4}^{3-}-\mathrm{P}$ & $-0.256^{* *}$ & $-0.190^{*}$ & $0.196^{*}$ & 0.040 & $-0.298^{* * * *}$ \\
\hline $\mathrm{COD}_{\mathrm{Mn}}$ & $0.315^{\text {**** }}$ & $0.294^{* * * *}$ & $-0.284^{* *}$ & 0.062 & $0.210^{*}$ \\
\hline DOC & $0.530^{* * *}$ & $0.563^{* * *}$ & 0.076 & $-0.312^{* *}$ & $0.279^{* *}$ \\
\hline $\mathrm{TN}$ & $-0.315^{\text {**** }}$ & $-0.449^{\text {**** }}$ & -0.087 & $0.309^{* * * *}$ & $-0.256^{* * *}$ \\
\hline $\mathrm{TP}$ & -0.003 & 0.031 & $0.343^{* * *}$ & -0.156 & $-0.180^{*}$ \\
\hline $\mathrm{N}: \mathrm{P}$ & $-0.193^{*}$ & $-0.255^{* *}$ & $-0.403^{\text {**** }}$ & $0.352^{* * * *}$ & 0.011 \\
\hline $\mathrm{SD}$ & 0.024 & 0.152 & $0.566^{\text {**** }}$ & $-0.535^{\text {**** }}$ & 0.089 \\
\hline Depth & -0.012 & -0.108 & $0.606^{* * * *}$ & $-0.473^{\text {**** }}$ & 0.007 \\
\hline WL & $0.234^{* * *}$ & $0.263^{* *}$ & $0.652^{* * *}$ & $-0.633^{* * *}$ & 0.159 \\
\hline $\mathrm{T}$ & $0.506^{\text {**** }}$ & $0.546^{\text {**** }}$ & $0.539^{* * *}$ & $-0.661^{* * *}$ & $0.223^{*}$ \\
\hline $\mathrm{pH}$ & $0.474^{* * * *}$ & $0.390^{\text {**** }}$ & -0.057 & $-0.258^{* *}$ & $0.364^{\text {**** }}$ \\
\hline ORP & 0.096 & 0.043 & $0.342^{\text {**** }}$ & $-0.301^{* * * *}$ & 0 \\
\hline DO & 0.170 & 0.109 & $-0.294^{\text {**** }}$ & $0.175^{*}$ & 0.056 \\
\hline $\mathrm{EC}$ & $0.384^{* * *}$ & $0.525^{* * *}$ & -0.170 & -0.162 & $0.396^{* * * *}$ \\
\hline Turb & 0.037 & -0.099 & $-0.575^{\text {**** }}$ & $0.485^{* * *}$ & -0.040 \\
\hline
\end{tabular}

*** 表示 $P<0.001 ; * *$ 表示 $P<0.01 ; *$ 表示 $P<0.001$.
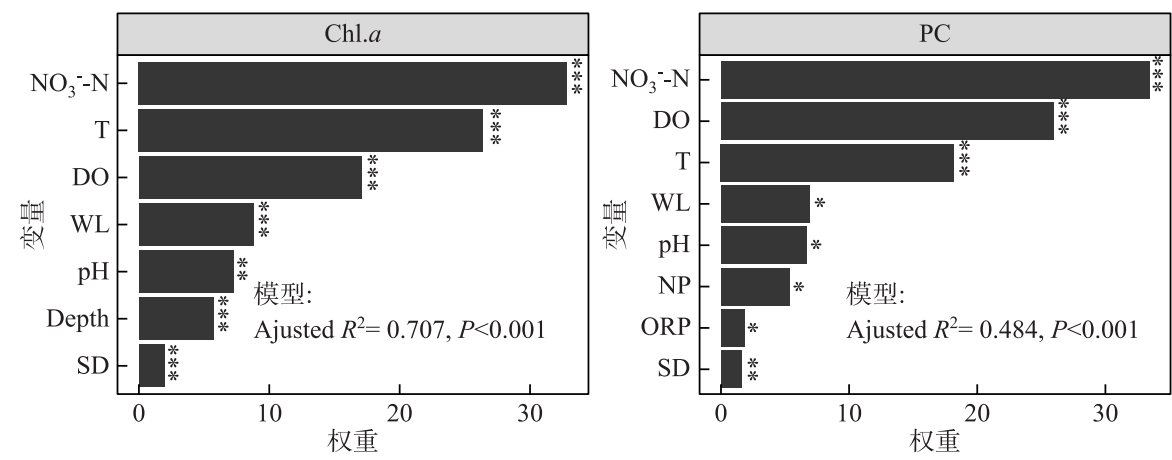

图 5 逐步回归分析中各变量相对权重柱状图 ( $* * *$ 表示 $P<0.001$; ** 表示 $P<0.01$; * 表示 $P<0.001$ )

Fig. 5 Bar plots of relative weights of the factors retained after stepwise regression analyses

\section{3 浮游藻类粒级结构变化及其与环境因子的关系}

如表 1 所示, 纳微型藻 $(3 \sim 20 \mu \mathrm{m})$ 是东洞庭湖浮游藻类生物量的主要贡献者, 全年平均占比为 $52.8 \%$; 
其次为超微型藻 $(<3 \mu \mathrm{m})$, 全年平均占比为 $31.1 \%$; 微型藻 $(>20 \mu \mathrm{m})$ 占比最低. 此外, 东洞庭湖浮游藻类 粒级结构还表现出明显的季节差异. 纳微型藻在冬季优势度最高, 平均高达 $68 \%$; 春季开始超微型藻所占比 例逐渐升高, 在夏季到达最高, 对浮游藻类总 Chl. $a$ 浓度的贡献量均值为 $42.1 \%$; 而微型藻 $(>20 \mu \mathrm{m})$ 占比最 低,全年平均占比 $16.2 \%$, 其比例在夏、秋季有所升高, 尤其是在总 Chl. $a$ 浓度最高的北湖湖区 (图 6).
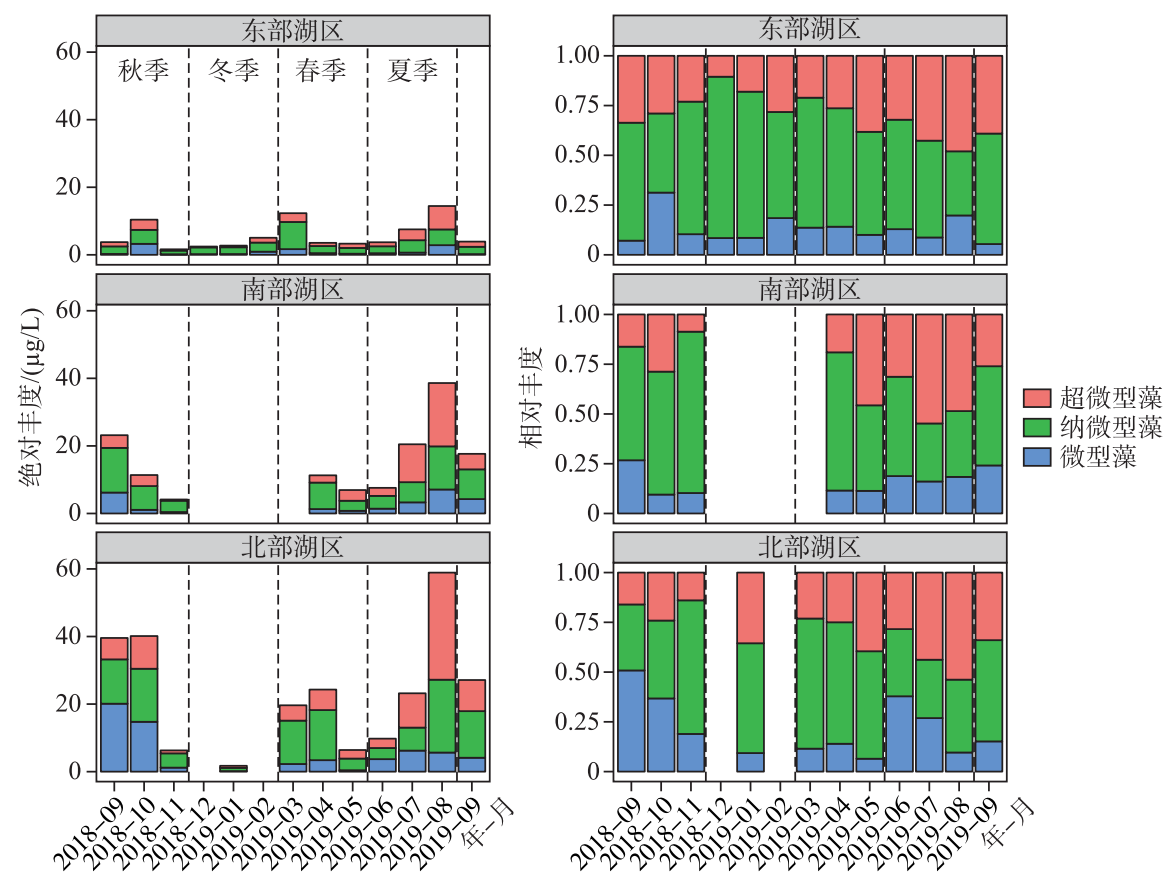

图 6 东洞庭湖不同湖区不同粒级浮游藻类绝对丰度和相对丰度组成变化

Fig. 6 Temporal variations of the absolute and relative compositions of different phytoplankton size components in east Lake Dongting

相关分析表明, 粒级最大的微型藻所占的比例与环境因子的相关性趋势与总 Chl. $a$ 浓度相似; 纳微型藻 所占的比例与水体营养盐浓度呈极显著正相关关系, 包括 $\mathrm{TN} 、 \mathrm{NO}_{3}^{-}-\mathrm{N} 、 \mathrm{NH}_{3}-\mathrm{N} 、 \mathrm{~N}: \mathrm{P}$ 等 $(P<0.001)$, 而与水温、 水位、透明度和 DOC 等均呈极显著负相关 $(P<0.01)$; 粒径最小的超微型藻所占的比例则与 $\mathrm{NH}_{3}-\mathrm{N} 、 \mathrm{COD}_{\mathrm{Mn}}$ 、 $\mathrm{N}: \mathrm{P} 、 \mathrm{DO}$ 和 Turb 呈显著负相关 $(P<0.05)$, 而与 TP、透明度、水位和水位等呈极显著正相关 $(P<0.001$, 表 2$)$. 进一步利用 RDA 分析了浮游藻类粒级组成对环境因子整体的响应趋势, 并结合环境因子预选篮选出对浮 游藻类粒级组成变化解释率最高的环境因子; 结果表明, 不同粒级浮游藻类绝对生物量对环境因子具有相 似的响应趋势, 而相对生物量则呈现不同的响应趋势 (图 7). 水温、透明度、水位、 $\mathrm{pH} 、 \mathrm{TN} 、 \mathrm{PO}_{4}^{3-}-\mathrm{P}$ 和 Turb 等 是影响东洞庭湖浮游藻类 Chl. $a$ 生物量粒级结构组成的关键因子. 在丰水期高水位、高水温的水体中超微型 藻类更具竞争优势, 而纳微型藻更适宜在透明度较低的低温水体中生长; 粒径最大的微型藻对高 $\mathrm{pH}$ 的耐受 性最高,而且随氮、磷浓度的增加比例降低.

\section{3 讨论}

本研究通过对东洞庭湖为期一年的调查发现, 东洞庭湖年度 TN 和 TP 浓度分别为 1.49 和 $0.10 \mathrm{mg} / \mathrm{L}$, 与鄱阳湖 ( TN : $1.72 \mathrm{mg} / \mathrm{L}$; TP : $0.13 \mathrm{mg} / \mathrm{L}$ ) 相当 ${ }^{[22]}$; 其中, TN 浓度均显著低于太湖 ( $2.52 \mathrm{mg} / \mathrm{L}$ ) 和巢湖 ( TN $2.69 \mathrm{mg} / \mathrm{L})$, 而 TP 浓度却几乎与太湖 $(0.12 \mathrm{mg} / \mathrm{L})$ 、巢湖 $(0.16 \mathrm{mg} / \mathrm{L})$ 持平 ${ }^{[23]}$. 这可能与通江湖泊水位变化 引起的湖流增大, 加之浅水湖泊风浪作用, 导致底泥沉积营养盐释放有关. 本研究结果也发现, 在 5 月水位 上升期, 东洞庭湖水体 $\mathrm{TP}$ 和 $\mathrm{PO}_{4}^{3-}-\mathrm{P}$ 浓度均显著上升, 达到年度峰值, 表明湖流扰动显著增加了底泥沉积磷 

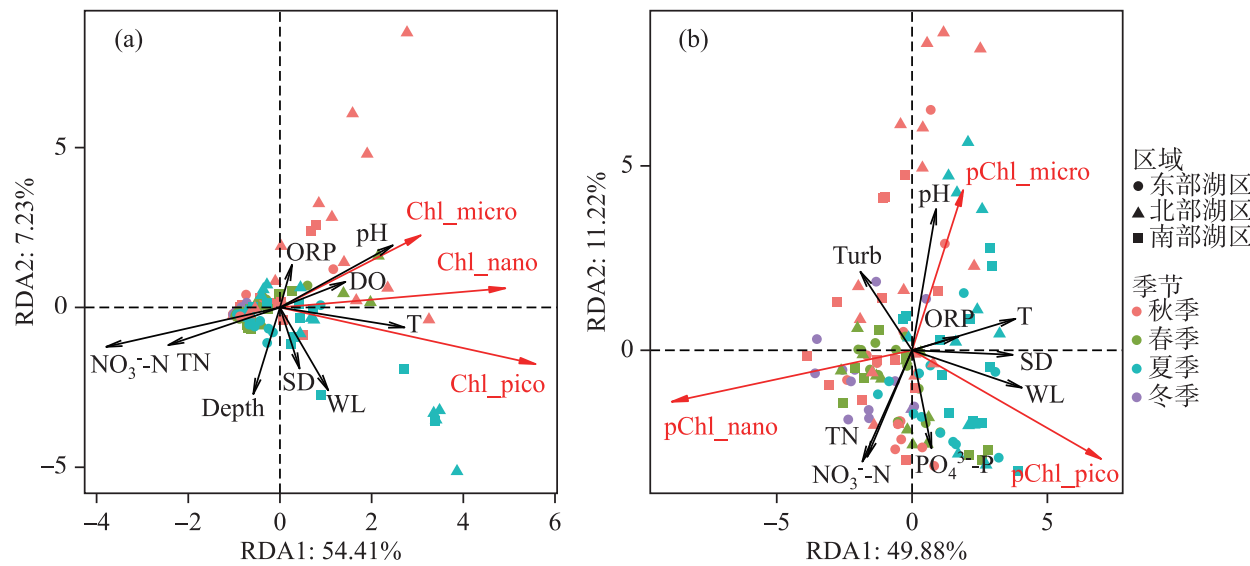

图 7 东洞庭湖不同粒级浮游藻类绝对组成 (a) 和相对组成 (b) 与环境因子的 RDA 分析

Fig.7 Redundancy analysis (RDA) triplots of the absolute (a) and relative (b) compositions of phytoplankton size fractions in east Lake Dongting

酸盐的释放; 另一方面, 外源补给也会对湖体营养盐浓度产生巨大影响 ${ }^{[24]}$,已有研究表明,洞庭湖人湖河口 营养盐均显著高于湖体和出湖口 ${ }^{[25]}$, 因此, 在水位上升期外来水体补给也可能是东洞庭湖 $\mathrm{PO}_{4}^{3-}-\mathrm{P}$ 浓度显著 升高的重要原因.

营养盐、温度和光照等水环境条件是影响水体浮游藻类生长的重要因素 ${ }^{[26]}$. 营养盐是浮游藻类生长的 物质基础 ${ }^{[27]}$,一般, 在水体较为稳定时, 水体营养盐的增加可显著促进藻类的生长 ${ }^{[28]}$. 而本研究发现, 在东 洞庭湖中浮游藻类 Chl. $a$ 和 PC 浓度与水体氮、磷营养盐浓度等均呈现显著负相关关系, 说明营养盐仍是东 洞庭湖藻类生长限制性因子. 逐步回归分析结果表明, $\mathrm{NO}_{3}^{-}-\mathrm{N}$ 、 $\mathrm{T}$ 和 $\mathrm{DO}$ 是解释东洞庭湖浮游藻类总 $\mathrm{Chl} . a$ 和 PC 浓度变化相对权重最高的因子, 但它们对 PC 的解释率只有 $48 \%$, 表明还有其他影响蓝藻生长重要的因 子未被检测. 调查还发现, 东洞庭湖中蓝藻主要集中在夏季东洞庭湖北湖湖区, 这与蓝藻喜温特性的研究结

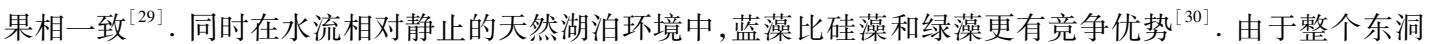
庭湖水流方向为自西向东, 自南向北经 $1^{\#}$ 点位君山汇人湘江洪道并于城陵矶注人长江(图 1); 因此, 属于湖 湾区的北部湖区, 尤其是大小西湖区, 由于没有人河口, 水体交换不畅, 是蓝藻水华高发区, 近年来观测到的 蓝藻水华均分布于此区域 ${ }^{[31]}$.

通过对浮游藻类生物量的分粒级研究发现, 东洞庭湖浮游藻类主要由纳微型藻组成, 这与包括海洋在 内的其他生境中的研究结果相似, 粒径在 2 20 $\mu \mathrm{m}$ 中等粒径的纳微型浮游藻类是水体中浮游藻类的主要贡 献者 ${ }^{[18,32-33]}$. 超微型藻是东洞庭湖浮游藻类生物量的第二大贡献者,平均占比超过 $30 \%$, 显著高于富营养化 严重的太湖和巢湖 (不到 $20 \%)^{[8]}$, 进一步表明随着湖泊营养条件的增加超微型藻所占比例不断降低. 这主 要是由于超微型藻细胞粒径小, 比表面积大, 营养吸收速率快, 因此, 在营养盐水平较低的水体中更具竞争 优势 ${ }^{[1]}$. 研究表明, 如果超微型藻能够长时间维持较高吸收速率, 那么在有瞬间的营养盐浓度波动的环境 中, 它们就更具有竞争优势 ${ }^{[34]}$; 而通江湖泊水动力条件十分复杂, 水环境条件变化频繁, 这也可能是超微型 藻在东洞庭湖优势度高的重要原因之一,尤其是在夏季水位上升期.

RDA 限制性排序结果表明,尽管不同粒级浮游藻类对环境因子的响应趋势相同,但适应能力不同; 主要 体现在环境因子对浮游藻类绝对生物量和相对生物量的影响结果不同 (图 7). 营养盐是控制浮游植物粒级 结构最重要的因素, 这主要是基于超微藻通常在塞营养水体中更占优势这一共识; 但也有例外, 如在营养盐 丰富的冬季, 小粒径的浮游藻类仍是浮游藻类生物量的主要贡献者 ${ }^{[35]}$. 这与冬季光的可利用性紧密相关, 冬季光照条件是影响浮游藻类粒级结构的重要因素之一, 因为小粒径个体细胞色素受包裹效应相对较少, 能更好地适应弱光环境 ${ }^{[11-12]}$. 此外, 温度也能显著影响浮游藻类的粒级结构, 生物个体大小一般随温度的升 高而逐渐降低,在冬季大粒径的藻类细胞或聚集体占优势, 而夏季浮游藻类生物量主要由小粒径藻类组 


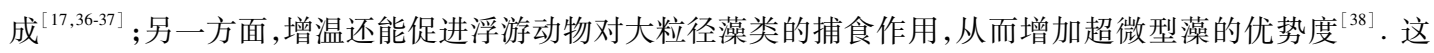
与本研究结果基本一致, 温度、透明度、水位、营养盐和 $\mathrm{pH}$ 是影响东洞庭湖游藻类粒级结构的重要因素, 粒 径最大的微型藻所占比例与高 $\mathrm{pH}$ 值、低营养盐浓度紧密相关, 纳微型藻在低温、低透明度水体中更具竞争 优势, 而温度上升、水位增加、浊度减小更利于超微型藻生长 (图 7b). 高 $\mathrm{pH}$ 值和低营养盐浓度环境可能是 由于藻类生物量大量生长, 消耗水体 $\mathrm{CO}_{2}$ 和营养盐, 引起水体 $\mathrm{pH}$ 升高所致 ${ }^{[39]}$, 也进一步表明大粒径藻类更 易受营养盐限制. 值得注意的是, 相关分析表明东洞庭湖超微藻所占比例与 SD 呈显著正相关 (表 2 , 图 7b), 这与小粒径藻类在弱光环境更具竞争优势的生态学原理相悖. 最近有研究报道, 在洪泛平原漫滩湖泊中粒 径最小的超微型藻是洪水来临时最先响应的藻类群体 ${ }^{[40]}$, 这与本研究超微藻与水位呈极显著正相关的趋势 一致 (表 2, 图 7b); 而环境因子相关分析表明东洞庭湖水体透明度与水温、水位均呈极显著正相关关系, 这 也可能是东洞庭湖超微藻与 SD 呈显著正相关的主要原因.

\section{4 结论}

1) 东洞庭湖浮游藻类 Chl. $a$ 和 PC 浓度均呈现显著的时空分布差异. 在空间上, 从北部湖区、南部湖区 到东部行洪道上依次降低; 在时间上, 冬季最低, 从春季开始逐渐上升, 到夏季达到峰值, 秋季开始逐渐降低.

2) $\mathrm{NO}_{3}^{-}-\mathrm{N} 、 \mathrm{~T}$ 和 DO 是解释东洞庭湖浮游藻类总 Chl. $a$ 和 PC 浓度变化最重要的因子.

$3)$ 纳微型藻 $(3 \sim 20 \mu \mathrm{m})$ 是东洞庭湖浮游藻类生物量的主要贡献者, 全年平均占比为 $52.8 \%$; 其次为超 微型藻 $(<3 \mu \mathrm{m})$; 微型藻 $(>20 \mu \mathrm{m})$ 占比最低. 东洞庭湖浮游藻类粒级结构还表现出明显的季节波动. 纳微 型藻在冬季优势度最高, 而夏季超微型浮游藻类贡献量显著增加.

4) RDA 限制性排序结果表明, 不同粒级浮游藻类对环境因子的响应趋势相同, 但适应能力不同. 温度、 水位、营养盐和 $\mathrm{pH}$ 等是影响东洞庭湖浮游藻类粒级结构的重要因素.

\section{5 参考文献}

[ 1 ] Raven JA. The twelfth tansley lecture. Small is beautiful: the picophytoplankton. Functional Ecology, 1998, 12(4) : 503513. DOI: 10.1046/j.1365-2435.1998.00233.x.

[ 2 ] Finkel ZV, Beardall J, Flynn KJ et al. Phytoplankton in a changing world: cell size and elemental stoichiometry. Journal of Plankton Research, 2010, 32(1) : 119-137. DOI: 10.1093/plankt/fbp098.

[ 3 ] Ward BA, Marañón E, Sauterey B et al. The size dependence of phytoplankton growth rates: a trade-off between nutrient uptake and metabolism. American Naturalist, 2017, 189(2) : 170-177. DOI: 10.1086/689992.

[ 4 ] Falkowski PG, Oliver MJ. Mix and match: how climate selects phytoplankton. Nature Reviews Microbiology, 2007, 5 (10) : 813. DOI: 10.1038/nrmicro1792.

[ 5 ] Chisholm SW. Phytoplankton Size//Falkowski PG ed. Primary productivity and biogeochemical cycles in the sea. New York: Springer US, 1992: 213-237.

[ 6] Bell T, Kalff J. The contribution of picophytoplankton in marine and freshwater systems of different trophic status and depth. Limnology and Oceanography, 2001, 46(5) : 1243-1248. DOI: 10.4319/lo.2001.46.5.1243.

[ 7 ] Callieri C. Picophytoplankton in freshwater ecosystems: the importance of small-sized phototrophs. Freshwater Reviews, 2007, 1(1) : 1-28. DOI: 10.1608/frj-1.1.1.

[ 8 ] Li S, Shi X, Lepère C et al. Unexpected predominance of photosynthetic picoeukaryotes in shallow eutrophic lakes. Journal of Plankton Research, 2016, 38(4) : 830-842. DOI: 10.1093/plankt/fbw042.

[ 9 ] Wang JJ. The spatio-temporal variation of phytoplankton community and size fractionated chlorophyll- $a$ in Baiyangdian Lake [Dissertation]. Baoding: Hebei University, 2011. [王军静. 白洋淀浮游植物时空分布及粒级研究 [学位论文]. 保 定: 河北大学, 2011.]

[10] Fu MZ, Sun P, Wang ZL et al. Seasonal variations of phytoplankton community size structures in the Huanghai( Yellow) Sea Cold Water Mass area. Acta Oceanologica Sinica, 2010, 32(1): 120-129. [傅明珠, 孙萍, 王宗灵等. 黄海冷水团 水域浮游植物群落粒级结构的季节变化. 海洋学报, 2010, 32(1) : 120-129.]

[11] Finkel ZV, Irwin AJ, Schofield O. Resource limitation alters the 3/4 size scaling of metabolic rates in phytoplankton. Marine Ecology Progress, 2004, 273(1) : 269-279. DOI: 10.3354/meps273269. 
[12] Finkel ZV. Light absorption and size scaling of light-limited metabolism in marine diatoms. Limnology and Oceanography, 2001, 46(1) : 86-94. DOI: 10.4319/lo.2001.46.1.0086.

[13] Marañón E. Cell size as a key determinant of phytoplankton metabolism and community structure. Annual Review of Marine Science, 2015, 7(7) : 241. DOI: 10.1146/annurev-marine-010814-015955.

[14] Acevedo-Trejos E, Brandt G, Bruggeman J et al. Mechanisms shaping size structure and functional diversity of phytoplankton communities in the ocean. Scientific Reports, 2015, 5(8918) : 8918. DOI: 10.1038/srep08918.

[15] Sun XX, Ren LL, Zheng S et al. Phytoplankton size structure in the Yellow Sea and East China Sea in the spring and summer of 2011. Oceanologia et Limnologia Sinica, 2012, 43(3) : 419-428. DOI: 10.11693/hyhz201203004004. [孙晓霞, 任琳琳, 郑珊等. 2011 年春夏季黄、东海浮游植物粒级结构. 海洋与湖沼, 2012, 43(3): 419-428.]

[16] Deng CM, Yu ZG, Yao P et al. Size-fractionated phytoplankton in the East China and Southern Yellow Seas and its environmental factors in autumn 2000. Periodical of Ocean University of China, 2008, 38(5) : 791-798. [邓春梅, 于志刚, 姚鹏等. 东海、南黄海浮游植物粒级结构及环境影响因素分析. 中国海洋大学学报: 自然科学版, 2008, 38(5): 791-798. ]

[17] Song L, Song GJ, Wang NB et al. The stress response of net phytoplankton biomass size structure in Liaodong Bay. China Environmental Science, 2015, 35(9): 2764-2771. [ 宋伦, 宋广军, 王年斌等. 辽东湾网采浮游植物粒级结构的胁迫 响应. 中国环境科学, 2015, 35(9): 2764-2771.]

[18] Yuan C, Xu Z, Zhang X et al. Seasonal changes of chlorophyll- $a$ and size structure in Shengzhen bay from November 2010 to August 2011. Marine Environmental Science, 2016, 35(6): 888-893. [袁超, 徐宗军, 张学雷等. 2010-2011 年深 圳湾 Chl. $a$ 与粒级结构的季节变化. 海洋环境科学, 2016, 35(6) : 888-893.]

[19] Xiong J, Yu FQ, Tian Q et al. The envolution of water quality and nutrient condition in Lake Dongting in recent 30 years. J Lake Sci, 2016, 28(6) : 1217-1225. DOI: 10.18307/2016.0607. [熊剑, 喻方琴, 田琪等. 近 30 年来洞庭湖水质营 养状况演变特征分析. 湖泊科学, 2016, 28(6): 1217-1225.]

[20] Jin XC ed. Control and management techniques of lake eutrophication. Beijing: Chemical Industry Press, 2011. [ 金相灿. 湖泊富营养化控制和管理技术. 北京: 化学工业出版社, 2001.]

[21] Yan R, Kong FX, Han XB. Analysis of the recruitment of the winter survival algae on the sediments of Lake Taihu by fluorometry. J Lake Sci, 2004, 16(2) : 163-168. DOI: 10.18307/2004.0210. [阎荣, 孔繁翔, 韩小波. 太湖底泥表层越 冬藻类群落动态的苂光分析法初步研究. 湖泊科学, 2004, 16(2) : 163-168.]

[22] Zhou J, Li SN, Wang XJ et al. Spatial distribution characteristics of picophytoplankton and its impact factors during wet season in Lake Poyang. J Lake Sci, 2016, 28(3) : 537-544. DOI: 10.18307/2016.0309. [周建, 李胜男, 王秀娟等. 丰 水期鄱阳湖超微型浮游植物空间分布特征及其影响因子. 湖泊科学, 2016, 28(3): 537-544.]

[23] Li SN. Community structure of picophytoplankton and their responses to elevated $\mathrm{CO}_{2}$ concentrations in eutrophic lakes [Dissertation]. Nanjing: Nanjing Institute of Geography and Limnology, Chinese Academy of Sciences, 2017. [李胜男. 富营养化湖泊超微型浮游藻类群落结构特征及其对 $\mathrm{CO}_{2}$ 升高的响应 [学位论文]. 南京: 中国科学院南京地理与 湖泊研究所, 2017.]

[24] Zha HM, Zhu MY, Zhu GW et al. Seasonal difference in water quality between lake and inflow/outflow river of Lake Taihu, China. Environmental Science, 2018, 39(3) : 1102-1112. DOI: 10.13227/j.hjkx.201707184. [查慧铭, 朱梦圆, 朱广伟等. 太湖出人湖河道与湖体水质季节差异分析. 环境科学, 2018, 39(3) : 1102-1112.]

[25] Wang Y, Jiang X, Li YF el al. Spatial and temporal distribution of nitrogen and phosphorus and nutritional characteristics of water in Dongting Lake. Research of Environmental Sciences, 2014, 27(5): 484-491. [王岩, 姜霞, 李永峰等. 洞庭 湖氮磷时空分布与水体营养状态特征. 环境科学研究, 2014, 27(5) : 484-491.]

[26] Zhang M, Shi X, Yang Z et al. Long-term dynamics and drivers of phytoplankton biomass in eutrophic Lake Taihu. Science of the Total Environment, 2018, 645: 876-886. DOI: 10.1016/j.scitotenv.2018.07.220.

[27] Xu H, Qin BQ, Zhu GW. Nutrient limitation of cyanobacterial growth in different regions of Lake Taihu in summer. China Environmental Science, 2012, 32(12) : 2230-2236. [许海, 秦伯强, 朱广伟. 太湖不同湖区夏季蓝藻生长的营养盐 限制研究. 中国环境科学, 2012, 32(12): 2230-2236.]

[28] Wu P, Deng JM, Qin BQ et al. Effects of enhanced water temperature and nutrient concentration on algal growth in winter and spring season in Lake Taihu, China. Research of Environmental Sciences, 2013, 26(10): 1064-1071. [吴攀, 邓建 明, 秦伯强等. 水温和营养盐增加对太湖冬、春季节藻类生长的影响. 环境科学研究, 2013, 26(10) : 1064-1071.] 
[29] Yang Y, Zhu XZ, Zhang M et al. Response patterns of different algae to the interaction between temperature and phosphorus. J Lake Sci, 2016, 28(4) : 843-851. DOI: 10.18307/2016.0418. [杨燕, 朱雪竹, 张民等. 不同藻类对温度与磷叠 加作用的响应模式. 湖泊科学, 2016, 28(4): 843-851.]

[30] Qian KM, Liu X, Duan M et al. Distribution and its influencing factors of bloom-forming cyanobacteria in Poyang Lake. China Environmental Science, 2016, 36 (1) : 263-269. [ 钱奎梅, 刘霞, 段明等. 鄱阳湖蓝藻分布及其影响因素分析. 中国环境科学, 2016, 36(1): 263-269.]

[31] Xue Y, Zhao YL, Zhang W et al. Chracteristics of spatial and temporal distribution of water blooms of outbreak in Dongting Lake based on MODIS data. Wetland Science, 2015, 13(4): 387-392. [薛云, 赵运林, 张维等. 基于 MODIS 数据的 2000 2013 年洞庭湖水华暴发时空分布特征. 湿地科学, 2015, 13(4) : 387-392.]

[32] Lai JX, Qin XL, Jiang FJ et al. Distribution of size-fractionated chlorophyll-a and its controlling factors in the surface waters of Qinzhou bay. Marine Environmental Science, 2016, 35(5):685-691. [赖俊翔, 覃仙玲, 姜发军等. 钦州湾表层 水分粒级 Chl. $a$ 分布特征及其影响因素. 海洋环境科学, 2016, 35(5) : 685-691.]

[33] Zhao W, Xing H, An LH. The contribution of algal picoplankton to phytoplankton bimasses and primary production in freshwater bodies in Dalian. Journal of Dalian Fisheries University, 2001, 16(3)：157-162. [赵文, 邢辉, 安立会. 不同 粒级浮游植物对淡水初级生产力的作用. 大连水产学院学报, 2001, 16(3): 157-162.]

[34] Stockner JG, Shortreed KS. Response of Anabaena and Synechococcus to manipulation of nitrogen: phosphorus ratios in a lake fertilization experiment. Limnology and Oceanography, 1988, 33( 6 part 1) : 1348-1361. DOI: 10.4319/lo.1988.33. 6.1348 .

[35] Clarke A, Meredith MP, Wallace MI et al. Seasonal and interannual variability in temperature, chlorophyll and macronutrients in northern Marguerite Bay, Antarctica. Deep Sea Research Part II: Topical Studies in Oceanography, 2008,55 (18) : 1988-2006. DOI: https://doi.org/10.1016/j.dsr2.2008.04.035.

[36] Zohary T, Fishbein T, Shlichter M et al. Larger cell or colony size in winter, smaller in summer-a pattern shared by many species of Lake Kinneret phytoplankton. Inland Waters, 2017, 7 (2) : 200-209. DOI: 10.1080/20442041.2017.1320505.

[37] Liu ZL, Cai YM, Cheng ZY et al. The distibution feature of chlorophyll- $a$ and primary productivity in Pryde Bay and its north sea area during the Austral summer of 1998/1999. Chinese Journal of Polar Reasearch, 2002, 14(1) : 12-21. [刘子 琳, 蔡昱明, 陈中元等. 1998/1999 年南极夏季普里兹湾及北部海区叶绿素 a 和初级生产力的分布特征. 极地研 究, 2002, 14(1): 12-21.

[38 ] Yvon-durocher G, Montoya JM, Trimmer M et al. Warming alters the size spectrum and shifts the distribution of biomass in freshwater ecosystems. Global Change Biology, 2011, 17(4) : 1681-1694. DOI: 10.1111/j.1365-2486.2010.02321.x.

[39] Zhao XH, Kong FX, Xie W et al. Effect of enhanced $\mathrm{CO}_{2}$ level on the physiology and ecology of phytoplankton. Acta Ecologica Sinica, 2012, 32(21): 6880-6891. DOI: 10.5846/stxb201109141345. [赵旭辉, 孔繁翔, 谢薇薇等. 全球 $\mathrm{CO}_{2}$ 水平升高对浮游植物生理和生态影响的研究进展. 生态学报, 2012, 32(21)：6880-6891.]

[40] Palijan G. Short-term response of the phytoplankton size structure to flooding. Inland Waters, 2017, 7(2) : 192-199. DOI: $10.1080 / 20442041.2017 .1325591$. 